International Conference on Ceramics, Bikaner, India

International Journal of Modern Physics: Conference Series

Vol. 22 (2013) 701-707

(C) World Scientific Publishing Company

DOI: $10.1142 / \mathrm{S} 201019451301088 \mathrm{X}$

\title{
LASER IN CERAMICS PROCESSING
}

\author{
BAJRANG LAL \\ Deptt. Of Physics, Engineering College, Bikaner. \\ Bikaner, Rajasthan, 334001, India \\ PANKAJ JAIN \\ Deptt. Of Physics, ECB Polytechnic College, Bikaner. \\ Bikaner, Rajasthan, 334001, India
}

\begin{abstract}
LASER, an acronym for Light Amplification by Stimulated Emission of Radiation have unique properties, Which make it differ from ordinary light such as it is highly coherent, monochromatic, negligible divergence and scattering loss and a intense beam of electromagnetic radiation or light. It also occur in a wide range of wavelength/frequency (from Ultraviolet to Infrared), energy/power and beam-mode/configurations ; Due to these unique properties, it have use in wide application of ceramic processing for industrial manufacturing, fabrication of electronic circuit such as marking, serializing, engraving, cutting, micro-structuring because laser only produces localized heating, without any contact and thermal stress on the any part during processing. So there is no risk of fracturing that occurs during mechanical sawing and also reduce Cost of processing. The discussion in this paper highlight the application of laser in ceramics processing.
\end{abstract}

\section{Introduction}

New laser technology is improving the economics and convenience of ceramic processing. Ceramics has been used in electronic applications for many years. However, with the recent commercial boom in electronic devices and the trend toward miniaturization, ceramic fabricators have sought more efficient and precise manufacturing methods and tools. The laser is one tool that has recently received much attention, in large part because advances in laser technology have improved the economics, efficiency and convenience of ceramic processing.

Laser processing of ceramics has a long history. However, laser use has primarily been limited to scribing applications involving fired alumina $\left(\mathrm{Al}_{2} \mathrm{O}_{3}\right)$ substrates using fast- and slow-flow carbon dioxide $\left(\mathrm{CO}_{2}\right)$ lasers. In the past, the size, reliability and operating cost of $\mathrm{CO}_{2}$ lasers prevented their widespread use in ceramics processing. But in recent years, technological advances have led to the development of entirely new sealed- $\mathrm{CO}_{2}$ and solid-state lasers that have overcome the drawbacks of early lasers, creating new applications and possibilities in ceramic processing. 


\section{Laser Applications}

Ceramic processing applications for lasers have increased since the development of several new industrial lasers. Lasers are now used to scribe, drill and profile, as well as for selective material removal and marking/serializing applications. They are used to process fired substrates of alumina, aluminum nitride (AlN) and beryllium oxide $(\mathrm{BeO})$, as well as unfired (green) substrates (see Table 1).

Table 1. Ceramic Processing applications and corresponding laser sources.

\begin{tabular}{ll}
\hline Process & Type of Laser \\
\hline $\begin{array}{l}\text { Scribing, Drilling and Profiling Fired Substrates } \\
\text { (Alumina,AIN,BeO) }\end{array}$ & $\mathrm{CO}_{2}$ Laser \\
Scribing, Drilling and Profiling Green Substrates & $\mathrm{CO}_{2}$ Laser/UV-DPSS Laser \\
Selective Material Removal & IR-/Green-/UV-DPSS Laser \\
Marking/Serializing & $\mathrm{CO}_{2}$ Laser/IR-/Green-/UV-DPSS Laser \\
\hline
\end{tabular}

\section{Selecting the Right Laser}

A laser is a non-contact, zero-wear tool capable of precisely delivering enormous amounts of photon energy to a specific and highly localized area for drilling, cutting, scribing or welding. The type of interaction that takes place depends on the properties of the material to be processed, as well as the wavelength and energy of light emitted by the laser. Figure 1 shows the wavelength of light and range of output power emitted by various types of lasers.

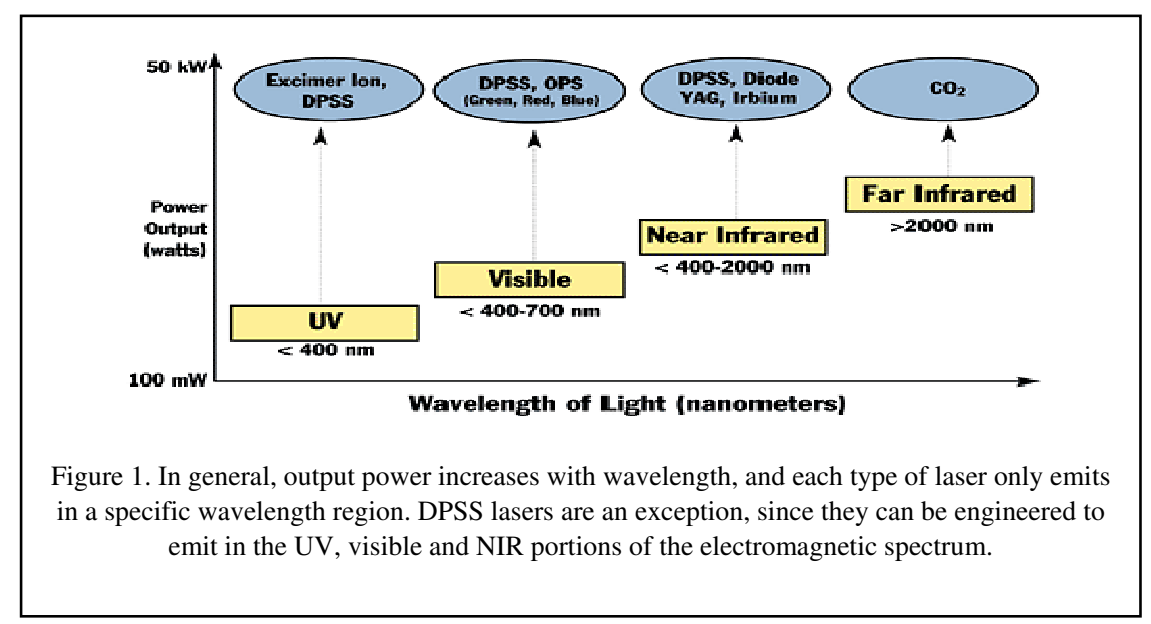

Modern ceramic processing uses two types of lasers: $\mathrm{CO}_{2}$ lasers that emit in the farinfrared (FIR) region of the spectrum, and diode-pumped solid-state (DPSS) lasers that are available at output wavelengths ranging from the ultraviolet (UV) through the visible to the near-infrared (NIR). 


\section{1. $\mathrm{CO}_{2}$ Lasers}

$\mathrm{CO}_{2}$ lasers emit in the FIR at a wavelength of 10.6 microns, which is easily absorbed by most ceramics. $\mathrm{CO}_{2}$ lasers also have high output powers, which allow high-speed processing and the processing of thick materials. Consequently, these lasers have been used by the ceramic industry for many years. However, in the past, only fast- and slowflow $\mathrm{CO}_{2}$ lasers using flowing-gas technology (where the lasing gas mixture flows through the laser cavity) were employed in these applications.

Flowing-gas lasers exhibit excellent output laser beam properties with $\mathrm{M}_{2}$ (a parameter indicative of beam quality) values ranging from 1.1 to 1.3 (the ideal value being 1.0). However, despite the fact that flowing-gas laser beams are suitable for ceramic processing, several factors have prevented their widespread use and acceptance by the ceramic industry. First, flowing-gas lasers are relatively large devices (in excess of $8 \mathrm{ft}$ in length) that occupy a considerable amount of shop floor space. Second, they are maintenance-intensive systems that require routine expert upkeep, including the replacement of optics and laser gases. Finally, the daily operating expenses of these lasers are high. For many years, these limitations made laser technology appear to be inconvenient, expensive and difficult to integrate.

By virtue of the slab-discharge design, sealed lasers are rugged and compact. They also require no replacement gases, and the head typically requires no maintenance for up to 20,000 hours (two and a half years) of continuous operation. Furthermore, the operating cost of sealed lasers is lower than that of flowing-gas lasers (see Table 2).

Table 2. Comparison of operating costs for $\mathrm{CO}_{2}$ lasers.

\begin{tabular}{llll}
\hline \multicolumn{1}{c}{$\mathrm{CO}_{2}$ Laser Type } & \multicolumn{1}{c}{ Sealed } & \multicolumn{1}{c}{ Slow-Flow } & \multicolumn{1}{c}{ Fast- Flow } \\
\hline Typical Average Power & 500 Watts & 1000 Watts & 1000 Watts \\
Peak Power & 1500 Watts & 10000 Watts & 3000 Watts \\
Maximum Repetition Rate & $100 \mathrm{kHz}$ & $2 \mathrm{kHz}$ & $5 \mathrm{kHz}$ \\
Laser Gas Consumption & 0 & 40 liter/hour & 73 liter/hour \\
Electrical Consumption & $8.5 \mathrm{kV} \mathrm{A}$ & $12 \mathrm{kV} \mathrm{A}$ & $35 \mathrm{kV} \mathrm{A}$ \\
Cooling-Water Flow & 9.5 liter/hour & 38 liter/hour & 77 liter/hour \\
Maintenance Period & $2.5 y e a r s$ & 6 month & 3 month \\
Average Hourly Operating Cost & $\$ 1.20$ & $\$ 2.50$ & $\$ 7.00$ \\
\hline
\end{tabular}

Another advantage of the sealed, slab-discharge design for ceramic processing is its fast pulsing capability. Slab-discharge lasers emit high-frequency pulses (up to $100 \mathrm{kHz}$ ) with up to $1.5 \mathrm{~kW}$ of peak power. The combination of high frequency and high peak power results in faster material processing, minimal thermal degradation and a smaller heat-affected zone (HAZ). 


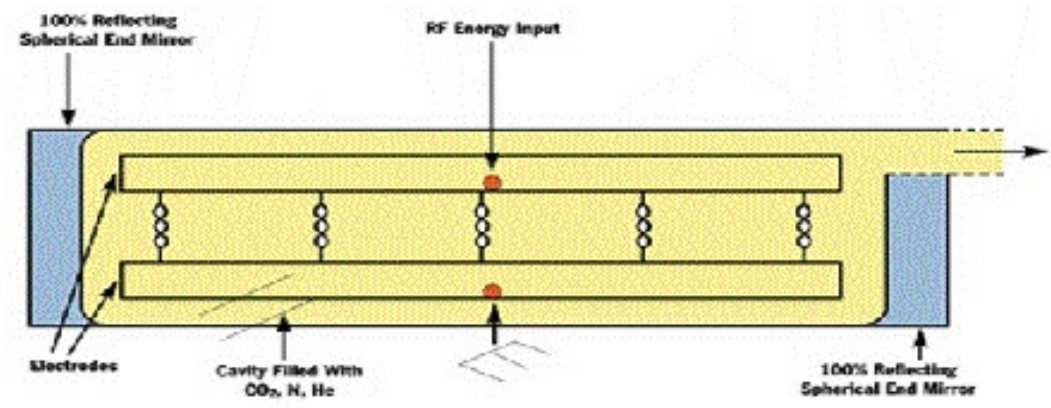

Figure 2. Seale a slabdis charge CO, berer concept. Recent technological develop ment have led to the invention of a different tpre of CO, bser incorporating seded, shb disc harge tec hov logy that overomes the lint itations of $e$ arlier lasers.

The shape of pulses emitted by sealed $\mathrm{CO}_{2}$ lasers also improves the quality of the drilled holes. Compared to flowing-gas lasers, sealed laser pulses exhibit short rise and fall times relative to the duration of the pulse, as well as a more square-wave pulse profile (see Figure 3). When pulse rise-times are long, the ceramic is needlessly heated before the pulse energy reaches the threshold required for material processing. When fall-times are long, the ceramic continues to be heated after processing. The result is an excessive HAZ. With sealed-laser pulses, energy is efficiently delivered for cutting or drilling, rather than for merely heating the material to be processed. The result is a cleaner cut or hole, better feature resolution and no heat-induced collateral damage.
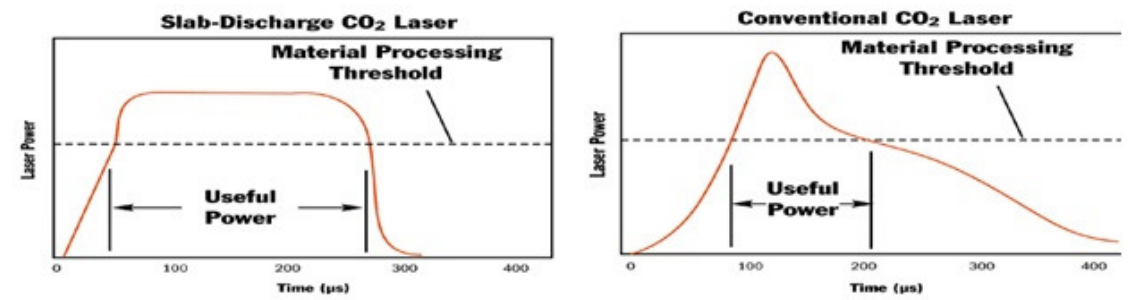

Figure 3. The fast rise and foll times of skb-discharge, sealed $\mathrm{CO}_{1}$ bser pulses result in amore efficient use of energy, thereby cousing less themal domage and inproving both hole quality and fature resolution. Conventional CO lasers with slow rise times and bne fall times needlessily heat the ceraric before and after processine.

Laser scribing is an application where the shape of laser pulses is very important. Laser scribing of a ceramic substrate consists of drilling a series of shallow, closely spaced holes. A pulse with slow rise and fall times leaves debris around the holes, glassy phase buildup around the sidewalls, and microfractures caused by thermal damage that extend into the surrounding substrate. In contrast, Figure 4 shows a $1 \mathrm{~mm}$ thick substrate of $96 \%$ alumina scribed with a sealed $\mathrm{CO}_{2}$ laser. The substrate was scribed with a series of $0.35 \mathrm{~mm}$ deep, $60 \mathrm{~mm}$ diameter holes. No microcracking occurred, and there was no glassy phase debris. 


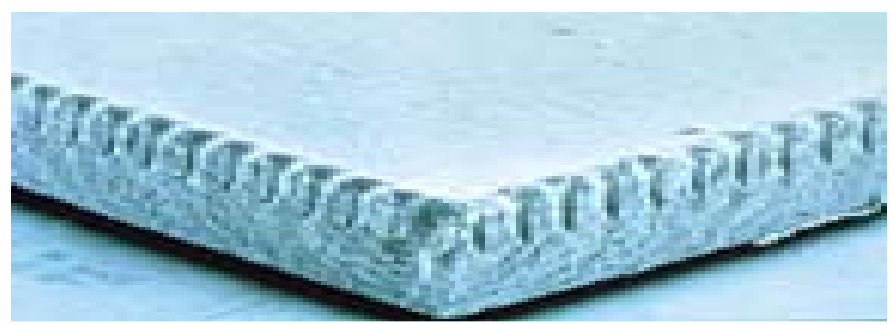

Figure 4. A 1-mm-thick substrate of $96 \%$ alumina scribed with a sealed $\mathrm{CO}_{2}$ laser reveals no microcracking and no glassy phase debris.

High-frequency pulsing also allows sealed lasers to quickly scribe and cut materials. Although scribing and cutting speeds are dependent on thickness, scribe depth and material, scribing speeds up to $12 \mathrm{~m} /$ minute and cutting speeds up to $500 \mathrm{~mm} /$ minute for $1.5 \mathrm{~mm}$-thick fired ceramic and $3.0 \mathrm{~mm}$ green ceramic are typical for a 100 -watt sealed $\mathrm{CO}_{2}$ laser. Figure 5 graphs the scribing speed of a 100-watt sealed laser for various scribe depths in $96 \%$ alumina.

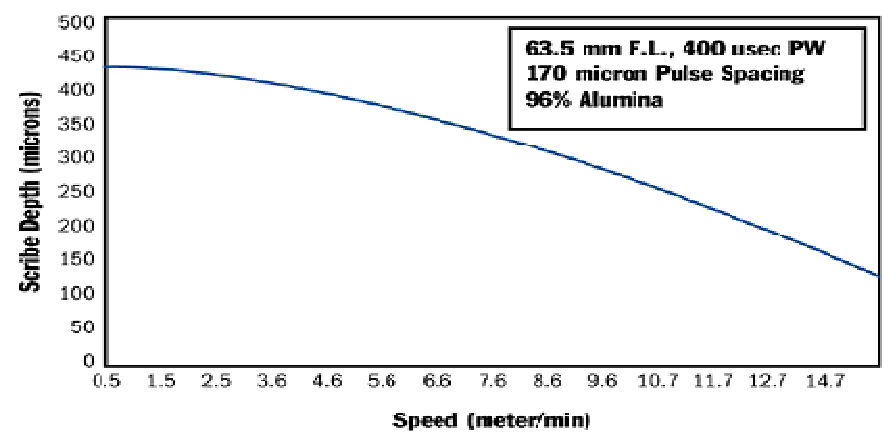

Figure 5. A $100 \mathrm{~W}$ sealed $\mathrm{CO}_{2}$ laser can scribe $96 \%$ alumina to a depth of $0.35 \mathrm{~mm}$ at a speed of $6.6 \mathrm{~m} / \mathrm{minute}$.

Via (or hole) drilling is another ceramic processing application where sealed $\mathrm{CO}_{2}$ lasers are commonly used. Their high-frequency output allows sealed lasers to drill vias with speeds up to 200 holes/second in green ceramic and 1 to 4 holes/second in fired ceramic. Of course, drilling speed also depends on the thickness of material and the diameter of the vias. Due to the long emission wavelength of $\mathrm{CO}_{2}$ lasers, they are only used to drill vias down to 50 microns in diameter. For smaller features, short wavelength UV lasers are used with compatible materials.

In general, the average output power of sealed $\mathrm{CO}_{2}$ lasers is lower than that of flowing-gas lasers. However, in most ceramic processing applications only $20 \%$ of the usable power of flowing-gas lasers is used. This is because the use of the full power would increase both thermal damage and the HAZ. Consequently, 1-kilowatt flowing-gas lasers are usually replaced with 250 or $150 \mathrm{~W}$ sealed lasers. In some cases, $500 \mathrm{~W}$ sealed 
lasers are used, with the output of the laser split four ways to simultaneously process four ceramic machining stations.

\subsection{Diode-Pumped Solid-State (DPSS) Lasers}

DPSS lasers used in ceramic processing are available in a variety of wavelengths, including $355 \mathrm{~nm}$ in the UV, $532 \mathrm{~nm}$ in the green portion of the visible spectrum, and $1064 \mathrm{~nm}$ in the near-infrared (NIR) region. The latest DPSS lasers contain one or more diode laser arrays that are used to continuously pump a rod of neodymium-doped vanadate (Nd:YVO4), and an acousto-optic Q-switch that is used to generate pulsed output. The fundamental output wavelength of Nd:YVO4 is in the NIR, at $1064 \mathrm{~nm}$. A second and third harmonic crystal is then used to transform the beam from 1064 to 355 nm wavelength.

The latest DPSS lasers are typically air-cooled units and have lower facilities requirements than $\mathrm{CO}_{2}$ lasers. With their all-solid-state design, they are also highly compact and rugged devices. Originally, solid-state lasers were flashlamp-pumped devices with low reliability, due to their aging and the thermal degradation of flashlamps, which had to be replaced every few hundred hours at great expense. However, leading manufacturers of today's DPSS lasers offer a minimum guaranteed time-to-service of 5,000 to 10,000 hours.

DPSS lasers are used for a variety of applications in the ceramic industry. Marking and serializing are most commonly performed with NIR DPSS lasers at $1064 \mathrm{~nm}$, due to their high processing speeds and minimal thermal damage. However, marking and serializing are sometimes performed with green $(532 \mathrm{~nm})$ and UV-DPSS $(355 \mathrm{~nm})$ lasers as well. DPSS marking speeds on a variety of materials range between 100 and 500 $\mathrm{mm} / \mathrm{second}$ at $1064 \mathrm{~nm}$ wavelength.

UV-DPSS lasers are used in ceramic processing applications where $\mathrm{CO}_{2}$ and other long wavelength lasers are unsuitable. These applications usually involve small feature sizes or require high-quality processing where no thermal degradation is tolerated and where speed of manufacturing is not the primary concern. The short wavelength of UVDPSS lasers $(355 \mathrm{~nm})$ compared with $\mathrm{CO}_{2}$ lasers $(10,600 \mathrm{~nm})$ allows them to focus down to smaller spots. Therefore, UV-DPSS lasers can more reliably drill smaller features $(25 \mathrm{~mm})$, such as vias, than $\mathrm{CO}_{2}$ lasers $(70 \mathrm{~mm})$.

\subsubsection{Comparing $\mathrm{CO}_{2}$ LASER with $U V$-DPSS lasers}

Compared to $\mathrm{CO}_{2}$ lasers, UV-DPSS lasers have relatively low output powers. Consequently, they are only used for processing thinner, uncured green ceramics. However, UV-DPSS lasers with a 50\% increase in output power have recently been developed. These units have average output powers in excess of $4.5 \mathrm{~W}$ at $355 \mathrm{~nm}$. In the future, units with even higher output power are expected, making these devices even more cost-effective. 


\section{Bringing Laser Mainstream}

New $\mathrm{CO}_{2}$ and DPSS laser technology has provided the potential to improve the economics and convenience of ceramics processing. Modern, no-maintenance sealed $\mathrm{CO}_{2}$ lasers featuring slab-discharge technology offer high-frequency pulsing and pulse shaping that improve feature quality and reduce HAZ. DPSS lasers are also now available in UV, visible and wavelengths with higher output powers. The convenience and cost effectiveness of these new lasers are making laser processing of ceramics a mainstream technique.

\section{References}

1. R.L. Schwoebel and E.J. Shipsey, J. Appl. Phys. 37, 3682 (2011)

2. D. Kandel and J.D. Weeks, Phys. Rev. B 49, 5554 (2011)

3. R. Leon, T.J. Senden, Y. Kim, C. Jagadish, and A. Clark, Phys. Rev. Lett. 78, 4942 (2012)

4. S. Tsukamoto, T. Honma, G.R. Bell, A. Ishii and Y. Arakawa, Phys. Rev. Lett 2, 386 (2011)

5. T. Ala-Nassila, R. Ferrando, and S.C. Ying, Adv. Phys. 51, 949 (2012)

6. H. Bulou and J.P. Bucher, Phys. Rev. Lett. 96, 076102 (2012)

7. D. Schiumarini, A. Balzarotti, Appl. Phys. Lett. 81, 2270 (2002)

8. O.V. Lysenko, V.S. Stepanyuk, W. Hegert, and J. Kirschner, Phys.Rev.B 68, 033409 (2009)

9. P.B. Joyce, T.J Krzyzewski, T.S. Jones, Phys. Rev. B 58, R15981(2010)

10. A. Ohtake and M. Ozeki, Appl. Phys. Lett. 78, 431 (2011) 